sible. Most of these patients are suffering from infectious conditions which in well-housed family circumstances would not require hospital admission either by reason of danger of infection, severity of disease, or because treatment could only be obtained in hospital.

In fact, of 431 patients admitted to the Western Hospital from this borough during 1962, only 21 were suffering from diseases notifiable by statute (10 of these being food-poisoning), and only 52 were suffering from diseases notifiable by regulation. The remaining 358 patients were suffering from non-notifiable infections such as mumps, chicken-pox, rubella, glandular fever, etc., for which isolation and/or treatment could not possibly be provided in the place at which they were living. In many cases they would not have been allowed to remain in residence.

Without expressing any views on the advisability or otherwise of trying to isolate dangerous notifiable infectious disease in general hospitals, and disregarding the possibility of epidemics or the recrudescence of virulence in diseases such as scarlet fever or measles, I suggest that it is essential to make adequate provision of infectious disease accommodation to which patients with notifiable and non-notifiable infectious conditions can be admitted when their housing circumstances preclude their isolation and treatment at home. It seems certain that if the Hospital Plan is implemented the very limited isolation accommodation proposed will be quite inadequate to accommodate the volume of cases of the type mentioned above.--I am, etc.,

Public Health Department, Royal Borough of Kensington,

\section{Diagnosis of Acute Appendicitis}

Sir,--We should be grateful for the exhaustive study of acute appendicitis in childhood by Dr. R. H. Jackson (August 3 , p. 277), and valuable lessons can be learnt from it. I think, however, that one of his conclusions may not be justified. He says that "in making the diagnosis of acute appendicitis the history of the disease is of less help to the doctor than the physical examination."

This may be true in the case of very young children and may be what Dr. Jackson intended to convey. I do not think it is true in older children, who can give good factual histories, and it certainly does not apply to adults. In fact the accurate diagnosis of acute appendicitis and many other acute abdominal conditions can often be made on the history while physical signs are misleading or absent. For instance, in acute appendicitis there may be little or no tenderness when an inflamed appendix is tucked well away from the somatic nerve supply of the abdominal wall behind the caecum or mesentery of the small gut.

Physical signs are of course all-important but must be considered together with the history. My own experience shows that accurate history-taking and interpretation of the history are often the vital factors in diagnosis.-I am, etc.,

London W.1.

$$
\text { E. E. O’Malley. }
$$

\section{Toxicity of Lignocaine}

SIR,---There has been correspondence recently concerning the toxicity of lignocaine. On this matter I would agree with those critics who state that those complaining have been using too strong a solution and that some effects described are essentially vasovagal.

Since the introduction of lignocaine I have used it for at least 5,000 operations, including about 100 gastrectomies, 150 cholecystectomies, about 100 prostatectomies, 70 or 80 Fothergill-type operations, and a good many colonic and other abdominal procedures, also numerous varicose veins and hernias. In all these, patients have been adequately premedicated with morphine, hyoscine, and sometimes pethidine. Minor surgery on out-patients is done without premedication.

In all this work I have yet to see gross toxic reaction to lignocaine, though we do notice an occasional mild bradycardia. Toxic reactions to adrenaline do occur from time to time, no more and no less often than when procaine was the anaesthetic drug, but have never been severe enough to require any treatment. For all this work the standard solution is $0.25 \%$ lignocaine, which is a fully effective anaesthetic agent. Adrenaline is added for all major work in the proportion of 1 in 200,000 in normotensives, 1 in 400,000 in hypertension and in certain other instances. The maximum quantity initially is up to $200 \mathrm{ml}$., but if necessary a further $100 \mathrm{ml}$. without adrenaline or $200 \mathrm{ml}$. with 1 in 400,000 adrenaline will be used to supplement anaesthesia or aid dissection.

With due respect to anaesthetists I prefer to do much of my work with local anaesthetic alone owing to the vast reduction in blood loss and greater ease of dissection-for example, in gastrectomies, prostatectomies, and vaginal repair work. In this hospital $0.5 \%$ solution is put up in $10-\mathrm{ml}$. containers, as some prefer it for finger work. I use it only for blocking major nerve trunks-for example, sciatic, when exposed in the course of an amputation.

A $2 \%$ solution without adrenaline is used to pour into the peritoneal cavity where a splanchnic block is not convenient and roaming round to explore the abdomen is necessary. The quantity is normally $25 \mathrm{ml}$. I will use more if, as in intestinal obstruction, a good deal spills out immediately after introduction.

I am writing this because I think it would be most unfortunate if this drug were to get a bad reputation. I believe that when properly used it is exceedingly safe.-I am, etc.,

\section{STEPHEN BARClay.}

Grey Hospital,

Greymouth, New Zealand.

\section{Collapse after " Parstelin"}

SIR,-With reference to the case reported under this heading by Drs. G. A. Low-Beer and D. Tidmarsh (September 14 , p. 683) it is noted that iproniazid (a monoamine-oxidase inhibitor) was given for three weeks until four days before the patient's death, when "parstelin" (tranylcypromine and trifluoperazine) was substituted.

In view of the well-known delayed excretion of monoamine-oxidase inhibitors, resulting in their presence in the body up to seven days after cessation of therapy, and their established property of potentiating the action of other drugs, especially other monoamine-oxidase inhibitors and central-nervous-system depressants, I would suggest that persistence of the action of iproniazid (a drug well known for its potential toxicity) might well have been responsible (in part at least) for the patient's death rather than any effect of parstelin or ephedrine either separately or in combination.I am, etc.,

London S.W.19.

H. LANTIN.

SIR,- The letters from Dr. J. C. Gates and from Drs. G. A. Low-Beer. and D. Tidmarsh (September 14, p. 683) raise some points of interest. Although Dr. Gates is correct in thinking that fluid retention does occur during the taking of tranylcypromine, it is rare and unassociated with paroxysmal side-effects. The diuresis referred to is misleading, since I have observed no change in urine output in the 24 hours following these effects in four patients. The sudden voiding of large quantities of urine after the attack subsides is more likely to be due to extraneous factors, such as inhibition of the bladder during the attack by fear. The effects of tranylcypromine on the sympathetic nervous system are complex. ${ }^{1-s}$ They include pressor effects which are probably central in origin and sympathetic blockade which is peripheral.

The death reported by Drs. Low-Beer and Tidmarsh raises points of greater importance. I believe that very few deaths have occurred during treatment with tranylcypromine alone, though many have occurred with the concomitant use of other drugs. The chief offenders are imipramine $e^{4-6}$ or pethidine ${ }^{7}$ or amphetamine-like agents. ${ }^{78}$ The synergism between tranylcypromine and amphetamine is well documented, and in view of the chemical and pharmacological similarity between these two drugs and between them and ephedrine it is not surprising to receive Dr. Low-Beer's and Dr. Tidmarsh's report. All three drugs inhibit amine oxidase, contain a propylamine side-chain, are central nervous stimulants, and are sympathomimetic. ${ }^{10}$ Tabulation of their side-effects shows them to be identical except that tranylcypromine is alone in causing the paroxysmal ones. ${ }^{12}$

It is likely that tranylcypromine produces its cardiac effects by interfering 